Supplement of Hydrol. Earth Syst. Sci., 25, 2009-2025, 2021

https://doi.org/10.5194/hess-25-2009-2021-supplement

(c) Author(s) 2021. CC BY 4.0 License.

(c) (i)

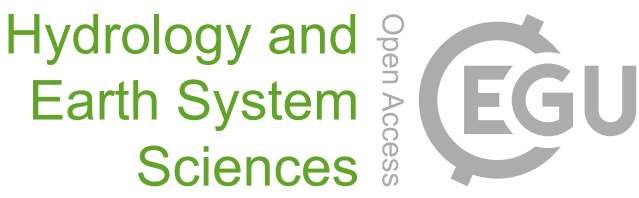

Supplement of

\title{
The development and persistence of soil moisture stress during drought across southwestern Germany
}

Erik Tijdeman and Lucas Menzel

Correspondence to: Erik Tijdeman (erik.tijdeman@uni-heidelberg.de)

The copyright of individual parts of the supplement might differ from the article licence. 
This supplementary material contains additional figures used for (1) the evaluation of the TRAIN model and (2) the sensitivity analyses investigating how the derived (controls on) SM stress characteristics change depending on the parameterization of the root zone or when investigating SM drought instead of stress.

\section{1. Model evaluation}

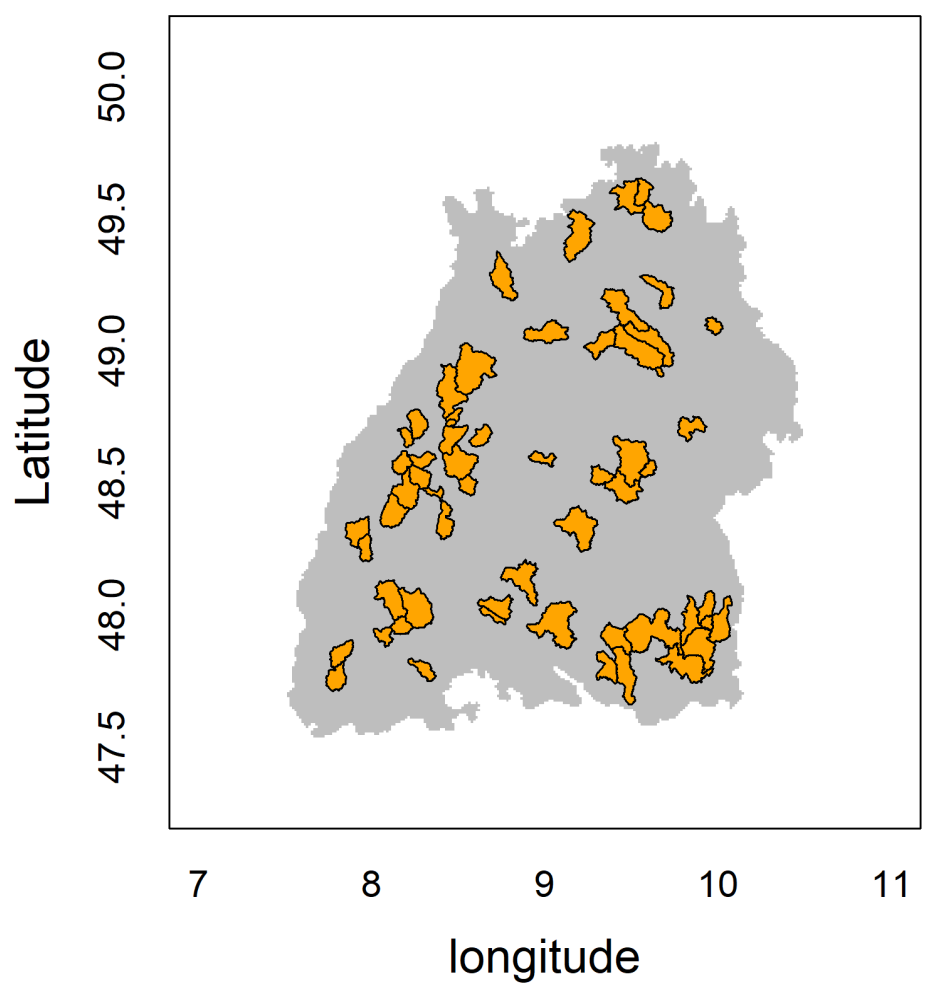

20 Figure S1. Locations of 60 catchments with near-natural flow used for the evaluation of the TRAIN model. 


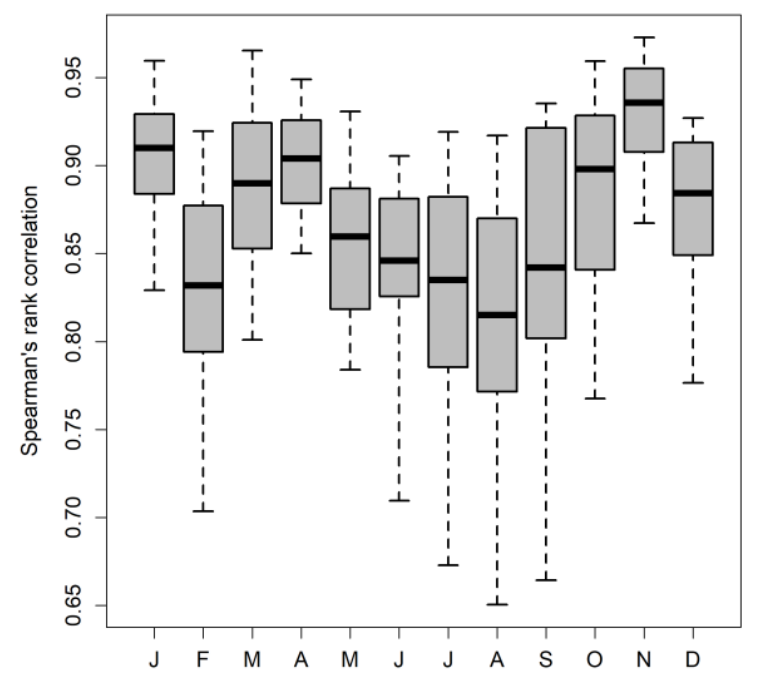

25 Figure S2. Maximum Spearman's rank correlation between monthly average river flow and the sum of simulated percolation and runoff accumulated over n-month periods $(n=1-12$ months). Derived for each catchment and calendar month separately, i.e., each boxplot is based on the maximum correlation values of 60 catchments. Box: percentiles 25,50 and 75 . End of whiskers: percentiles 5 and 95. 

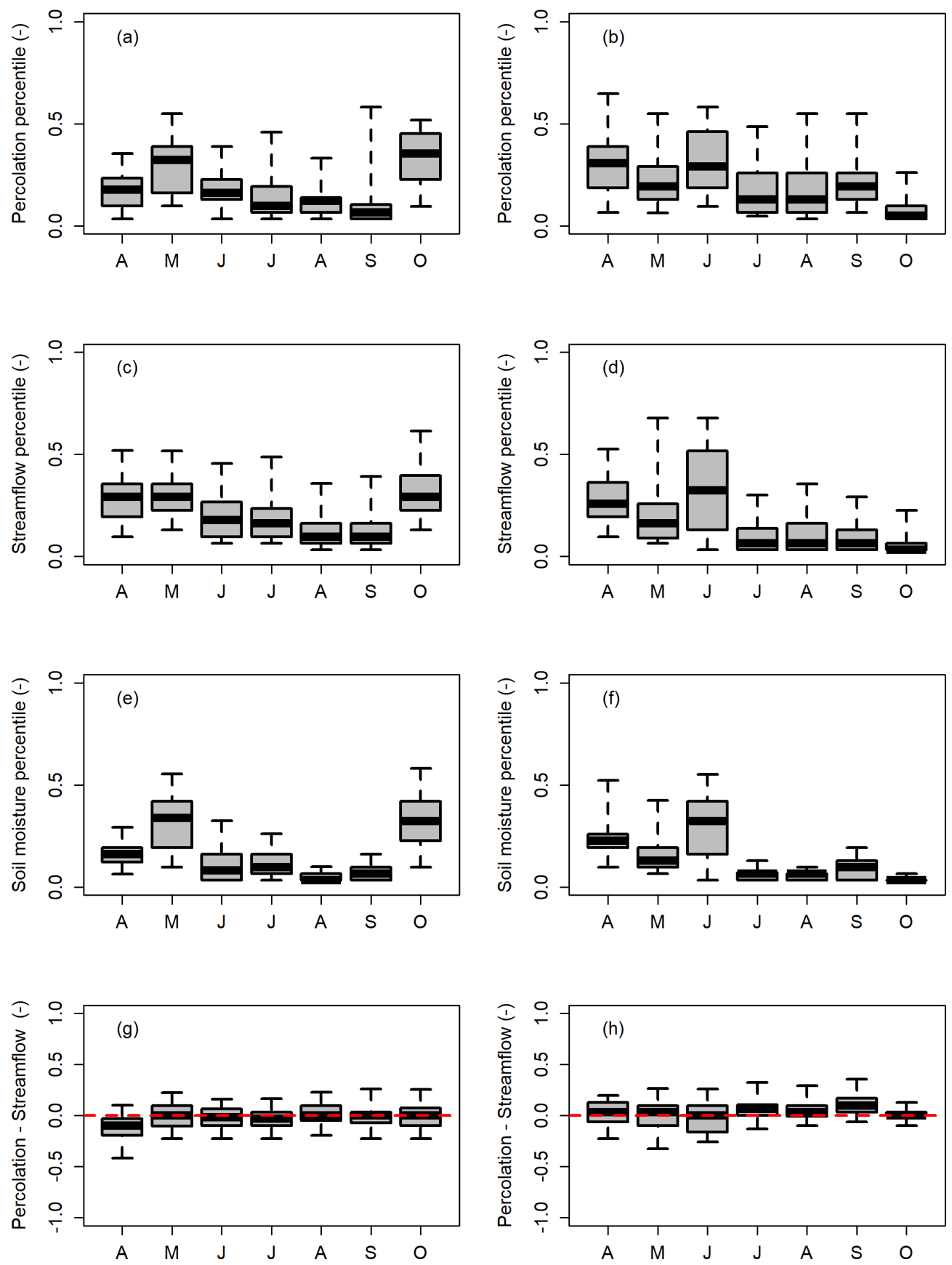

Figure S3. For all catchments and for the growing season of the two most prominent drought years 2003 and 2018: (a-b) percentiles of the sum of simulated percolation and runoff accumulated over the n-month period (1-12 months) with the maximum correlation with observed monthly river flow, (c-d) observed river flow percentiles, (e-f) simulated soil moisture percentiles, and (g-h) percolation percentiles minus river flow percentiles, i.e., observations in graphs a-b minus simulations in graphs c-d. Box: percentiles 25, 50 and 75. End of whiskers: percentiles 5 and 95. 

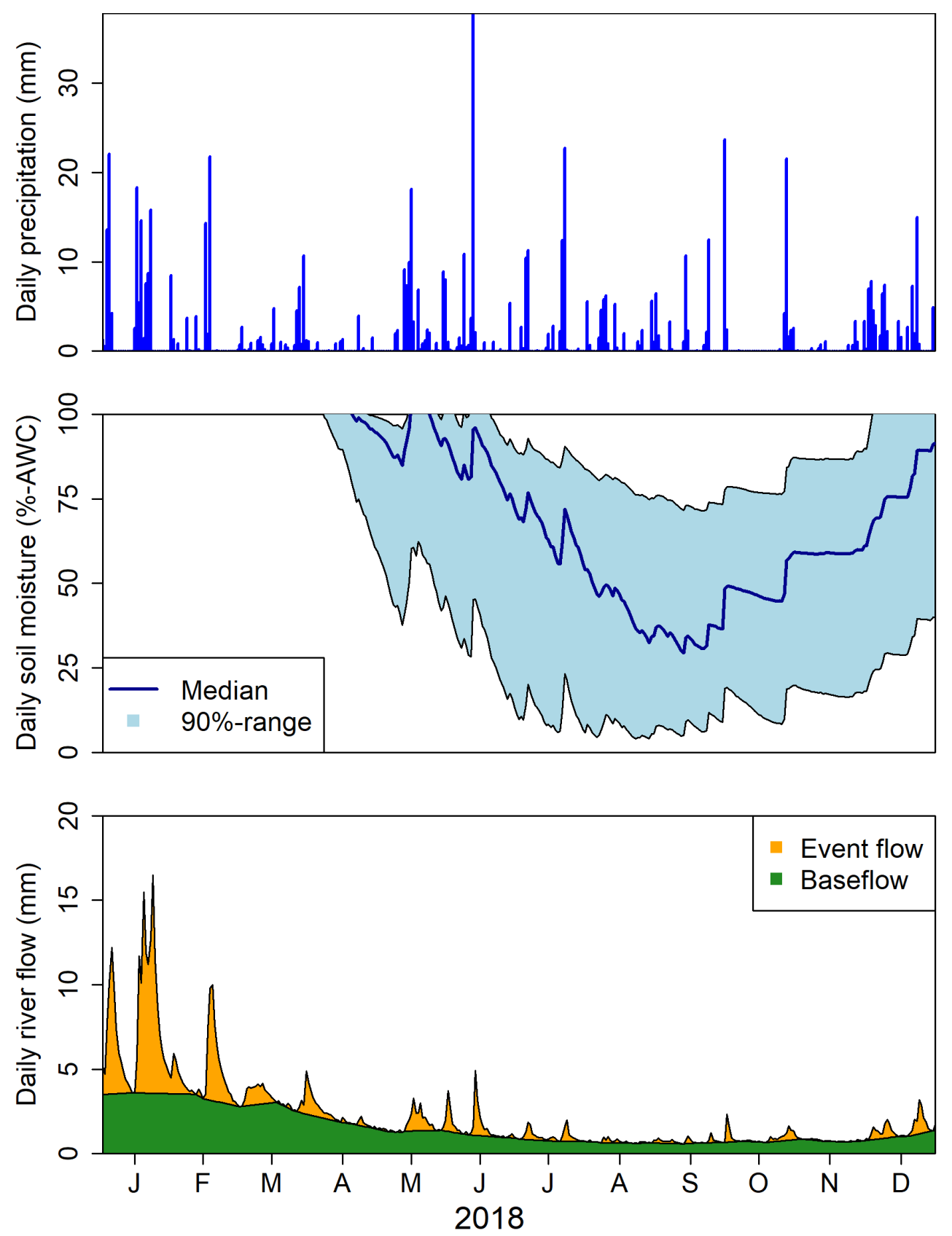

Figure S4. For one exemplary catchment (a): daily precipitation, (b) the variability and median of daily soil moisture for all grid cells within a catchment and (c) daily river flow; separated into a quick (event flow) component and a slow (baseflow) component using the base flow separation method described in Gustard and Demuth (2009). 


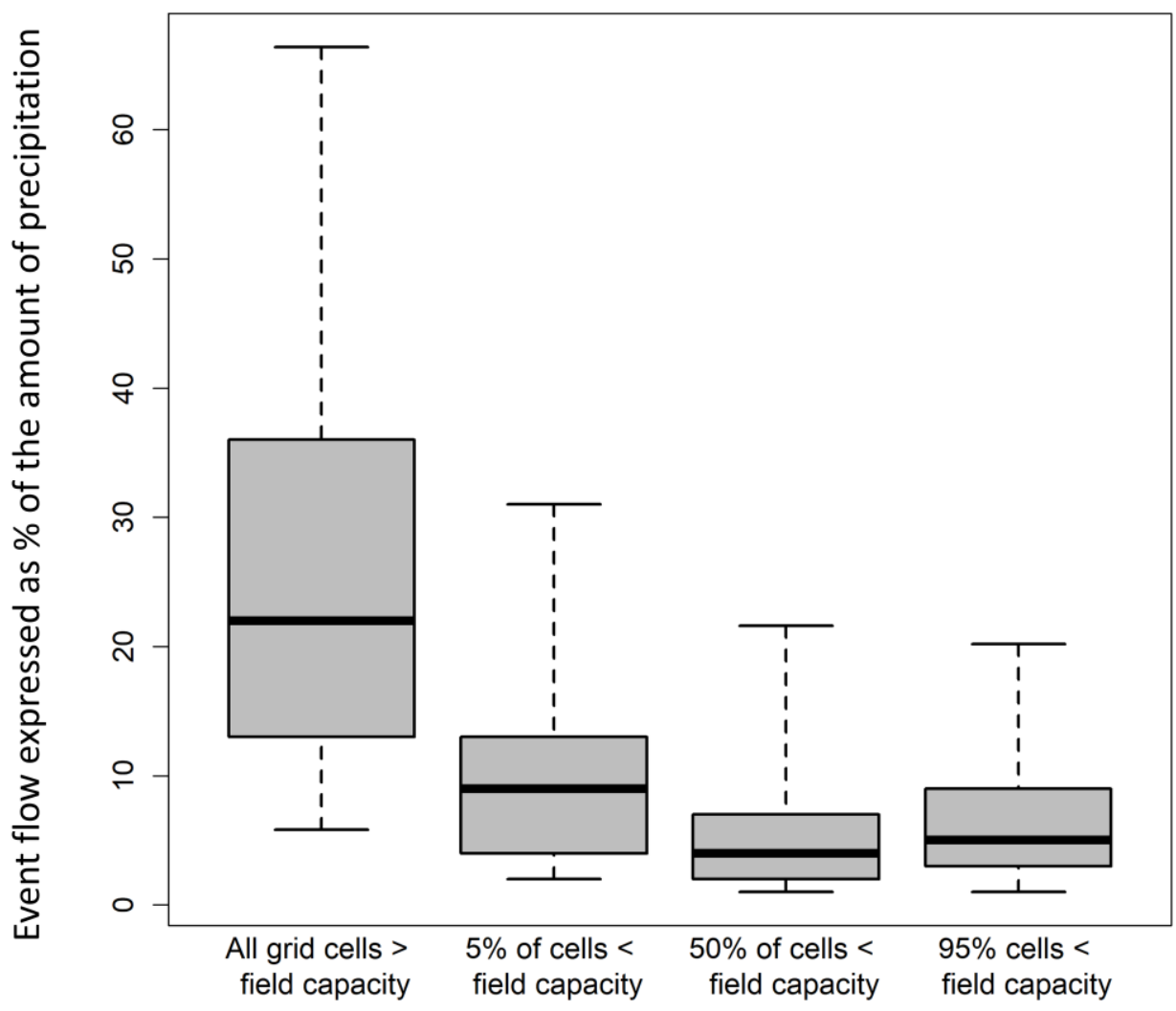

Figure S5. For all catchments: the volume of event flow expressed as the percentage of the volume of precipitation aggregated over periods whenever simulated soil moisture exceeds field capacity for all grid cell in the catchment or is below field capacity for a 45 certain percentage of grid cells in a catchment (resp. 5, 50 and 95 percent of grid cells). Box: percentiles 25, 50 and 75 . End of whiskers: percentiles 5 and 95. 

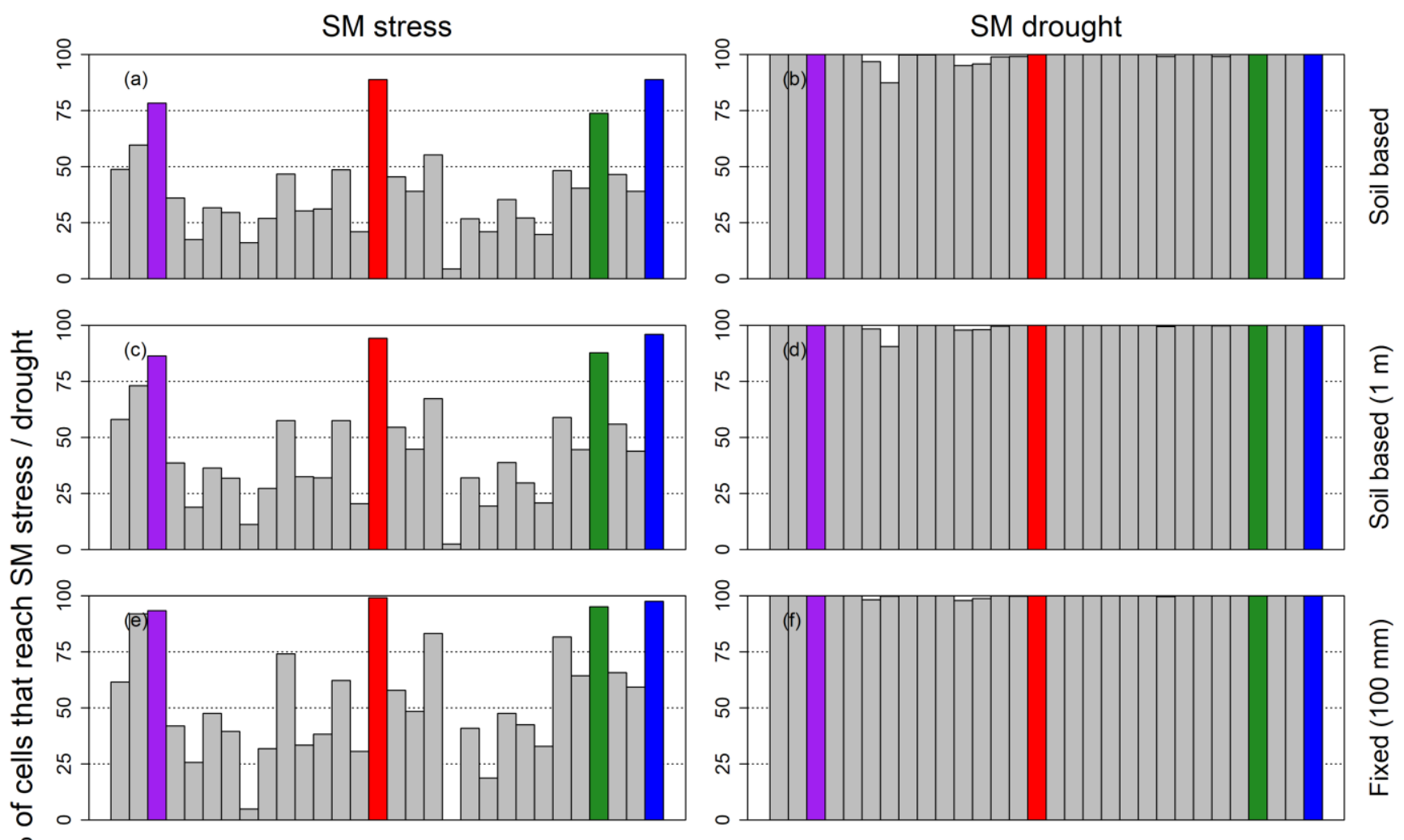

○
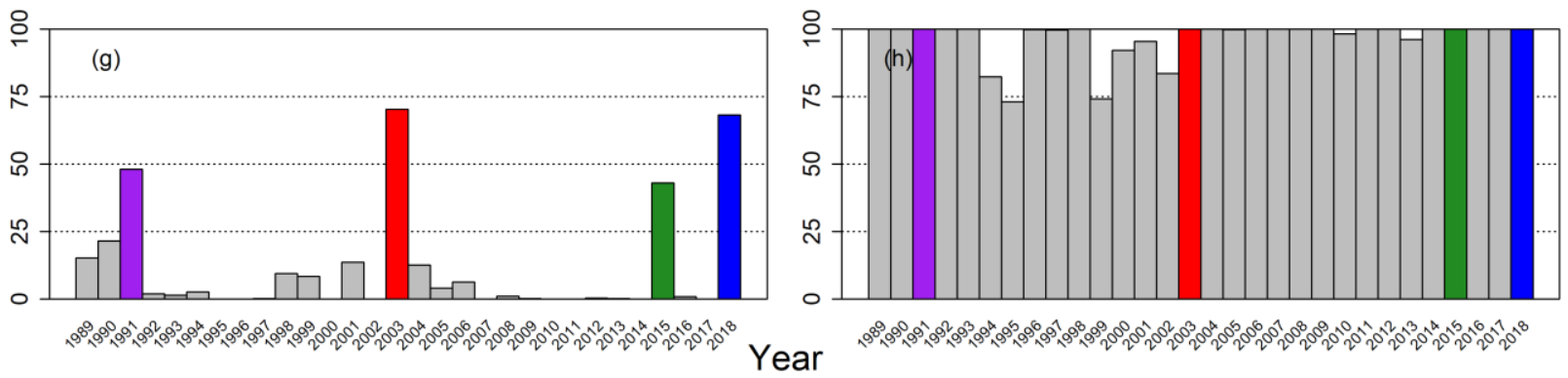

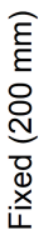

50 Figure S6. Similar to Fig. 6: percentage of cells that reached soil moisture stress (left column; a, c, e, g) or soil moisture drought (right column; $b, d, f, h)$ for at least one day in different calendar years with the most prominent drought years (1991, 2003, 2015 \& 2018) highlighted in color. Derived from simulations carried out for different parameterizations of the root zone: soil based (ab), soil based with the rooting depth constrained at one meter (c-d), a more shallow root zone with a fixed AWC of $100 \mathrm{~mm}$ (e-f) a deeper root zone with a fixed AWC of $200 \mathrm{~mm}(\mathrm{~g}-\mathrm{h})$. 


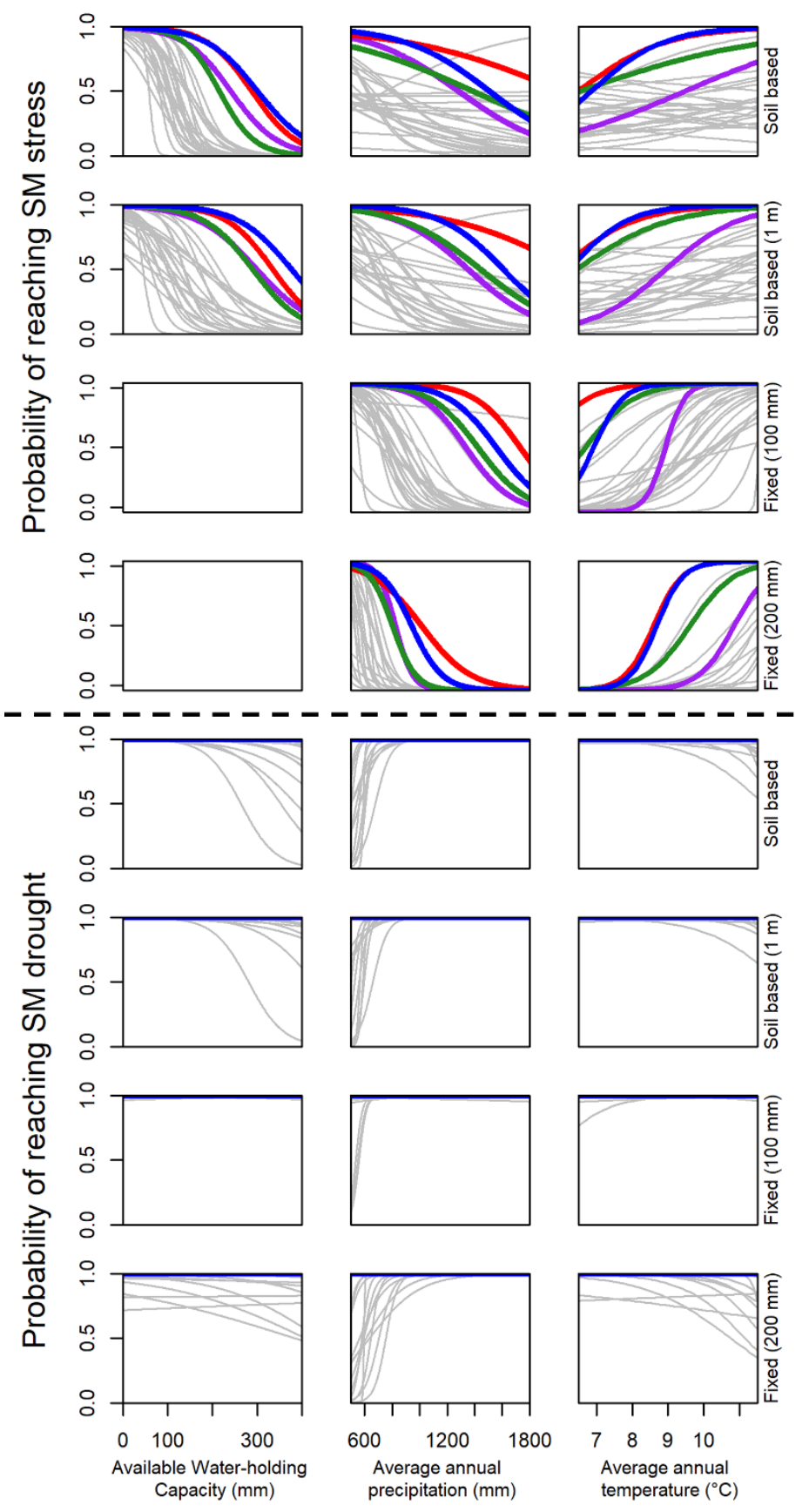

Figure S7. Similar to Fig. 7: probability of reaching soil moisture stress (upper four rows) or drought (lower four rows) at least once in a year as a function of (a) the available water-holding capacity of the root-zone, (b) annual average sum of precipitation, (c) annual average temperature. Each curve reflects the probability function of a different year and curves of prominent drought 60 years are highlighted in color (purple $=1991$, red $=2003$, green $=2015$, blue $=2018$ ). Derived from results using different parameterizations of the root zone: soil based (row $1 \& 5$ ), soil based with the rooting depth constrained at one meter (row $2 \& 6$ ), a more shallow root zone with a fixed AWC of $100 \mathrm{~mm}$ (row 3 \& 7) and, a deeper root zone with a fixed AWC of $200 \mathrm{~mm}($ row 4 and 8). 

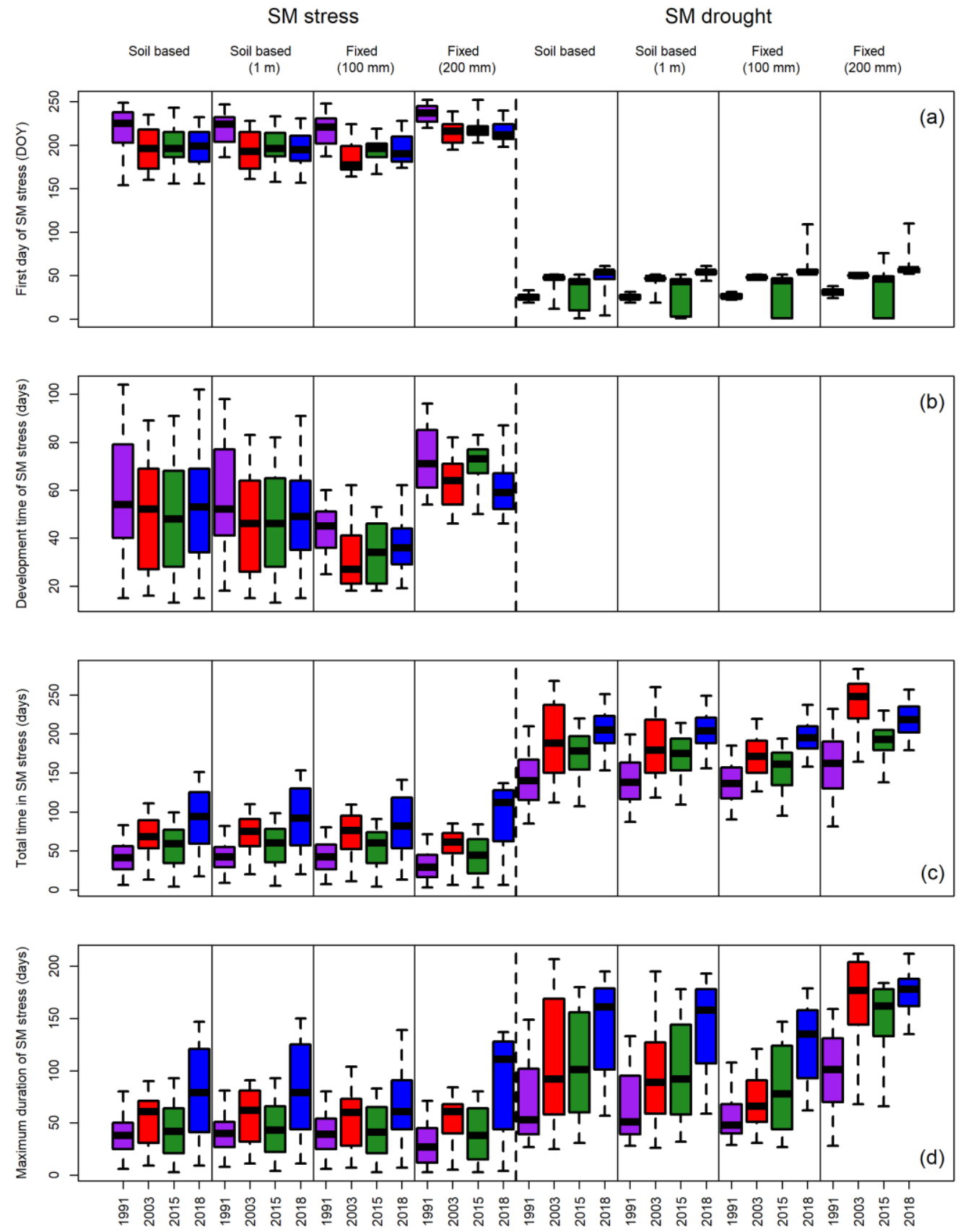

Figure S8. Similar to Fig. 8: variability of different soil moisture stress characteristics presented for the prominent drought years 1991 (purple), 2003 (red), 2015 (green) and 2018 (blue). Shown are (a) first day, (b) development time (c) total number of days, and (d) maximum duration of SM stress or drought. Box: percentiles 25, 50 and 75. End of whiskers: percentiles 5 and 95. 


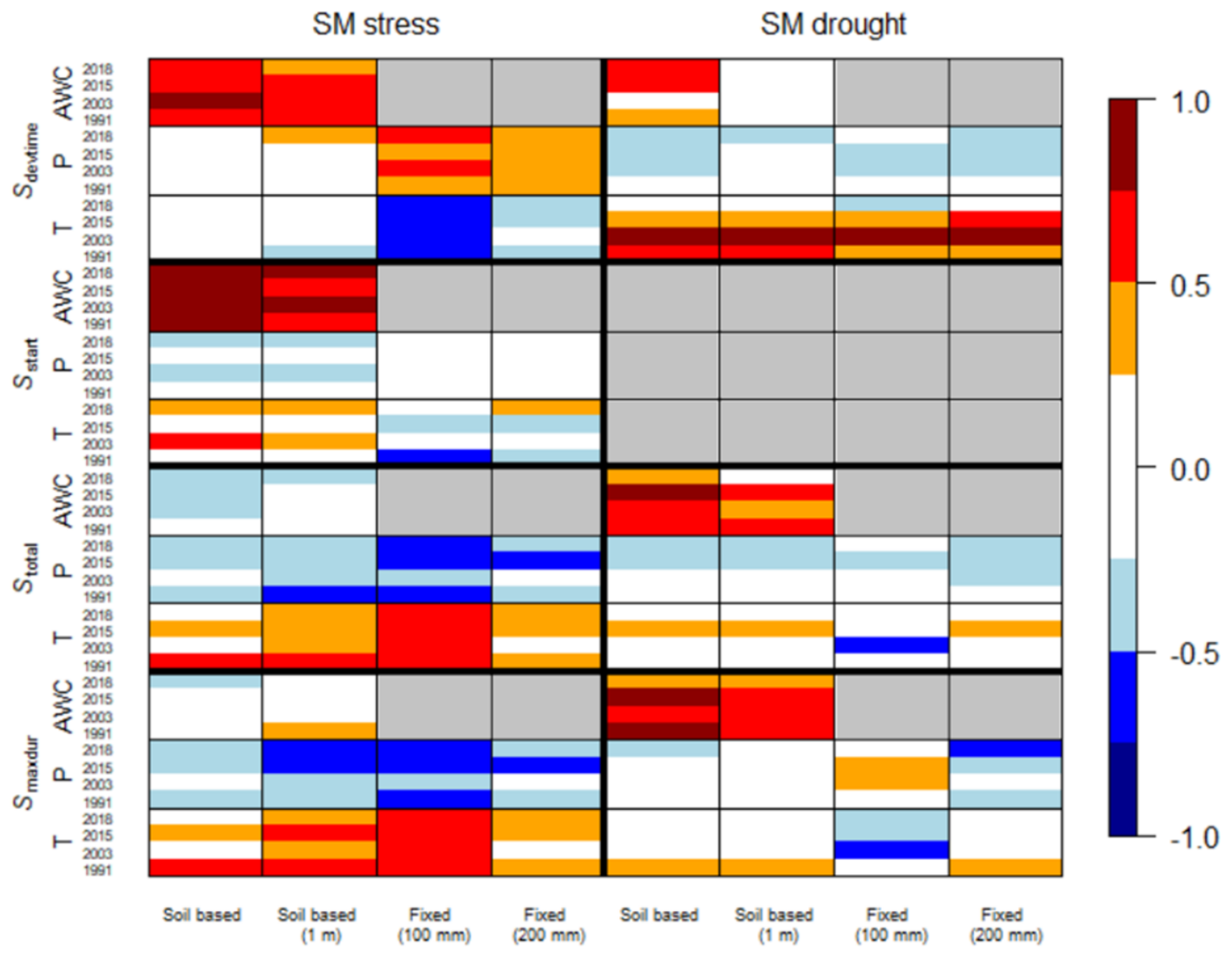

Figure S9. Similar to Table 1: Spearman's rank coefficient between different soil moisture stress (four left columns) and drought (four right columns) characteristics; first day $\left(S_{\text {start }}\right)$, development time $\left(S_{\text {devtime }}\right)$, total time $\left(S_{\text {total }}\right)$ and maximum duration $\left(S_{\text {maxdur }}\right)$, and different soil and climate controls; available water-holding capacity of the root zone (AWC), annual average precipitation ( $P$ annual $)$ and annual average temperature $\left(T_{\text {annual }}\right)$, during four prominent drought years $(1991,2003,2015,2018)$. 


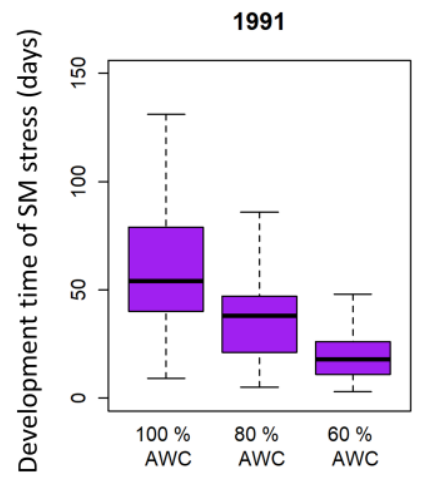

2003

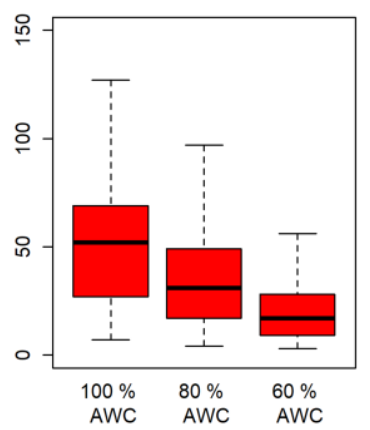

2015

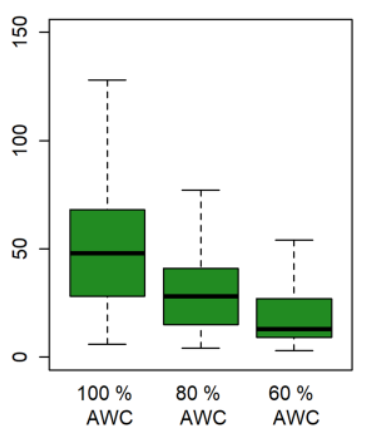

2018

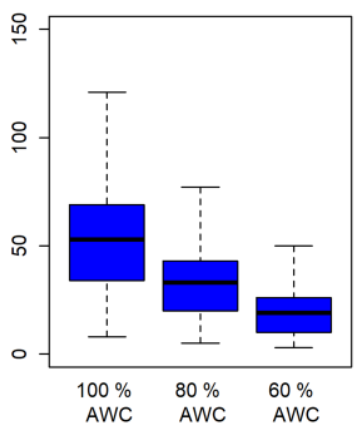

Starting point of SM stress development

Figure S10. Similar to Figure 8b: development time of SM stress during prominent years (1991, 2003, 2015 and 2018) using different levels of soil moisture as starting point (resp. 100, 80 and 60 percent of the AWC remaining in the root zone soil). 
SM stress

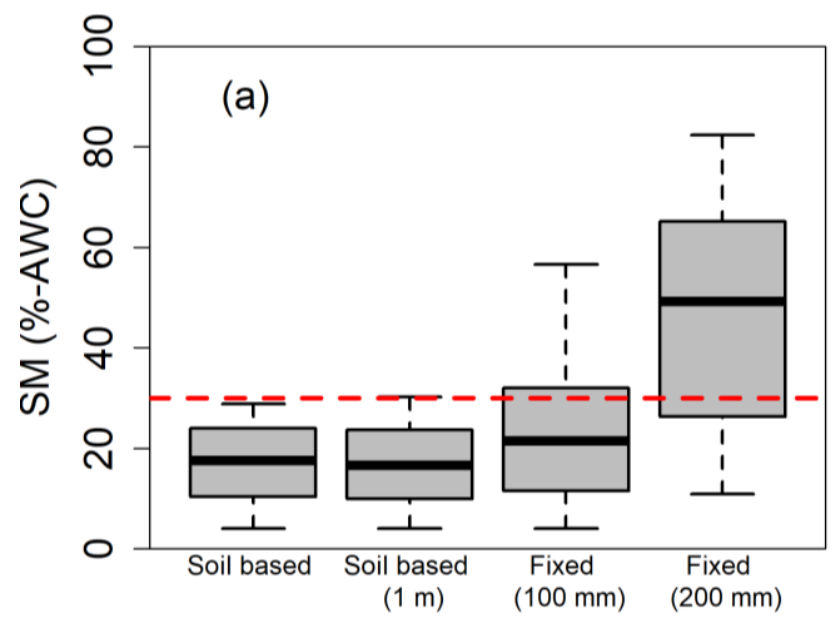

SM drought

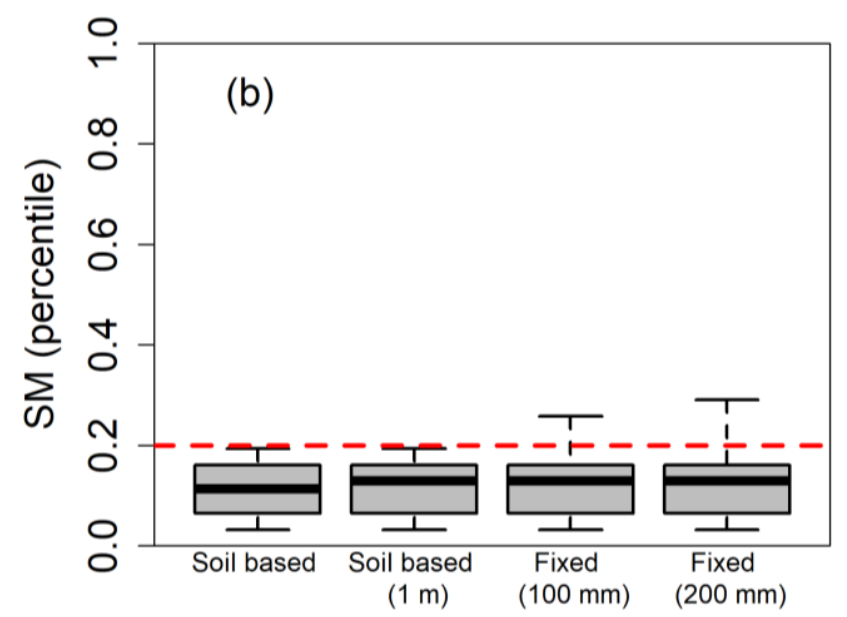

Figure S11. Soil moisture values (a) and anomalies (b) derived from results using different parameterizations of the root zone for all days soil moisture derived from a soil based root zone parameterization was in stress $\left(<30 \%\right.$-AWC, a) or drought $\left(<20^{\text {th }}\right.$ percentile, b). Box: percentiles 25, 50 and 75. End of whiskers: percentiles 5 and 95. 